\title{
Structural Performance of Reinforced Concrete Flat Plate Buildings Subjected to Fire
}

\author{
Sara J. George and Ying Tian* \\ (Received April 16, 2012, Revised May 17, 2012, Accepted May 17, 2012, Published online July 1, 2012)
}

\begin{abstract}
The research presented in this paper analytically examines the fire performance of flat plate buildings. The modeling parameters for the mechanical and thermal properties of materials are calibrated from relevant test data to minimize the uncertainties involved in analysis. The calibrated models are then adopted to perform a nonlinear finite element simulation on a flat plate building subjected to fire. The analysis examines the characteristics of slab deflection, in-plane deformation, membrane force, bending moment redistribution, and slab rotational deformation near the supporting columns. The numerical simulation enables the understanding of structural performance of flat plate under elevated temperature and, more importantly, identifies the high risk of punching failure at slab-column connections that may trigger large-scale failure in flat plate structures.
\end{abstract}

Keywords: elevated temperature, fire, flat plate, punching shear, slab.

\section{Introduction}

Reinforced concrete flat plate is a type of structural system containing slabs with uniform thickness supported directly on columns without using beams. Flat plates are commonly used in buildings where relatively low gravity loads are applied. A major concern for flat plates is punching failure of slab in the vicinity columns due to high stress concentration. In 2004, a flat plate parking garage collapsed in Gretzenbach, Switzerland after fire was ignited for $90 \mathrm{~min}$ inside the garage (Ruiz et al. 2010). The collapse, causing the death of seven firefighters, was triggered by punching failure of slab around one column that immediately propagated over the structure. In spite of this incident, very limited information exists regarding the vulnerability to punching failure of flat plate structures subjected to fire. Moss et al. (2008) numerically studied the fire resistance of a reinforced concrete building consisting of flat plates and conjunctionally used perimeter moment frames. Elevated temperatures simulating fires with and without decay phase were applied below the slab in the entire lowest story. The finite element analyses focused primarily on the vertical deflection, horizontal expansion, bending moment, and in-plane membrane force in the heated slab. However, the risk of slab punching failure was not specifically studied.

A flat plate under severe fire condition experiences significant load redistribution. When the fire load is applied

Department of Civil and Environmental Engineering and Construction, University of Nevada Las Vegas, 4505 S. Maryland Parkway, Las Vegas, NV 89119, USA. *Corresponding Author; E-mail: ying.tian@unlv.edu Copyright $($ The Author(s) 2012. This article is published with open access at Springerlink.com beneath the slab, columns restrain slab flexural deformation induced by thermal gradient, resulting in increased slab negative bending moment near the columns. Moreover, the slab top reinforcement remains relatively cool while bottom reinforcement heats up. The elevated temperature may cause the bottom bars at mid-span to yield at low stress. The load redistribution leads to high negative moment and large inelastic flexural deformation in slab near columns, which likely triggers to a punching failure of the flat plate structure. The study presented herein examines the punching failure potential of slab-column connections in flat plate buildings in the event of uncontrolled fire. For this purpose, nonlinear finite element analyses are performed on a prototype flat plate structure subjected to elevated temperature. The analysis determines the slab local force and deformation demands at columns as well as the degradation of punching shear strength. The research is limited to flat plates where the design of slabs is governed by gravity loads and the slabs are supported on square columns without using any shear reinforcement.

\section{Description of Finite Element Modeling}

\subsection{General Model and Experiments for Model Calibration}

The analyses are performed using Abaqus (Dassault Systèmes Simulia Corporation 2009), a general purpose finite element program. The span-to-thickness ratio of slab in a flat plate structure is normally larger than 30 . Four-node thin shell elements with reduced integration are therefore used to simulate reinforced concrete slabs. The mesh size is approximately equal to slab thickness. Simpson's rule is adopted for integration at a section to evaluate the slab 
internal forces. Thirteen integration points are defined at a section. The slab-column joint region is taken as rigid. Temperature variation through the thickness of slab is assumed to be piecewise quadratic. Perfect bonding between concrete and reinforcement is assumed. Concrete spalling under elevated temperature is not considered. Siliceous aggregate concrete, more vulnerable to fire-induced damage than carbonate concrete, is assumed for slabs.

To minimize uncertainty involved in analysis, several key modeling parameters for concrete are calibrated from relevant test data. The concrete tensile behavior that greatly affects slab flexural stiffness is calibrated from the tests of two isolated slab-column connections, Specimens B-2 and B-4, tested by Elstner and Hognestad (1956) in ambient temperature. These specimens are chosen because they had slab tensile reinforcement ratios $(0.55$ and $0.99 \%)$ representative of design practice. The slab of each specimen had identical geometry $(1,830 \times 1,830 \times 152 \mathrm{~mm})$ and the center column stub was $254 \mathrm{~mm}$ square. The slab reinforcing bars were uniformly distributed. No shear reinforcement was used. During the tests, the specimens were placed up-side-down and simply supported along slab edges with the slab corners free to lift up. A downward vertical load simulating the effects of concentric gravity loading was applied at the center column stub.

Three furnace tests of two-way reinforced concrete slabs performed by Lim and Wade (2002) are used to examine the definitions of concrete thermal properties specified in ASCE (1992) Manual No. 78 (referred to as ASCE in the following discussions for simplicity) and EC2 (1992). All the specimens (D147, HD12, and 661) were $3.3 \mathrm{~m}$ wide, $4.3 \mathrm{~m}$ long, and $100 \mathrm{~mm}$ thick slabs constructed using siliceous concrete with identical compressive strength (36.6 MPa). The type and amount of flexural reinforcement varied among the specimens. The slabs were simply supported at the four edges in the tests. The corners of Specimens 661 and HD12 were unrestrained from vertical displacement, but the corners of Specimen D147 were clamped down. In each test, constant gravity load of $5.4 \mathrm{kPa}$ was first applied first and then followed by a threehour standard fire.

\subsection{Mechanical and Thermal Properties of Reinforcement}

The slab flexural reinforcement is modeled as onedimensional material using Rebar Layer available in Abaqus. The reinforcement is assumed to be elastic-perfectly plastic under tension and compression. The modulus of elasticity at higher temperatures is defined following the recommendation by Harmathy (1993) for reinforcing steel. The mass density of reinforcing bars is taken as unchanged at high temperatures. The specific heat and conductivity of reinforcement are not included in the heat transfer analyses because the absence of reinforcing bars in the analyses has negligible effects on the temperature field in slabs (Wang 2004). The thermal expansion of reinforcement is defined based on Eurocode 3 (1995).

\subsection{Mechanical Properties of Slab Concrete}

Slab concrete under triaxial state of stresses is modeled using Concrete Damaged Plasticity (Lubliner et al. 1989; Lee and Fenves 1998). The five parameters needed to construct this model are assumed as temperature-independent: (1) Vermeer and De Borst (1984) suggested a non-associated plasticity for concrete where the dilation angle was defined with a value between $0^{\circ}$ and $20^{\circ}$. Due to the relative large range of this suggested value, the appropriate definition of dilation angle for use in the analyses of flat plates is calibrated from experiments, as discussed later; (2) a flow potential eccentricity of 0.1 is used because the dilatancy of concrete is known to vanish at high confining pressure (Vermeer and De Borst 1984); (3) based on experimental evidence (Lubliner et al. 1989), the ratio of the second stress invariant on the tensile meridian to that on the compressive meridian is defined as 0.667 ; (4) The viscosity parameter is taken as zero so that no viscoplastic regulation is enforced; (5) The ratio of initial equibiaxial compressive yield stress to initial uniaxial compressive yield stress ranges narrowly from 1.10 to 1.16 (Lubliner et al. 1989). A value of 1.16 is chosen for this ratio.

Since little is known about the effects of temperature on the Poisson's ratio of concrete, it is assumed as a constant value of 0.2. The Young's modulus and stress-strain response of concrete under uniaxial compression, as shown in Fig. 1, are defined tri-linearly according to EC2 (1992) as a function of temperature. The normalized stress in Fig. 1 is the ratio of stress at elevated temperature to concrete compressive strength at room temperature. Concrete under compression behaves linearly until reaching a stress of $0.45 f_{c}$, after which the material experiences strain hardening. Once the strength $f_{c}$ (peak stress) is reached, strain softening is initiated.

For simplicity, a bilinear model is adopted for concrete tensile behavior. The failure stress of concrete in tension, $f_{t}$, represents the onset of micro-cracking. Beyond $f_{t}$, the stressstrain curve softens to reflect the formation of micro-cracks and further reaches zero stress at $\varepsilon_{t u}$. Concrete tensile strength vanishes when temperature reaches up to $600{ }^{\circ} \mathrm{C}$. Note that there in no consensus regarding the definition of $f_{t}$. Concrete tensile strength was completely neglected in the

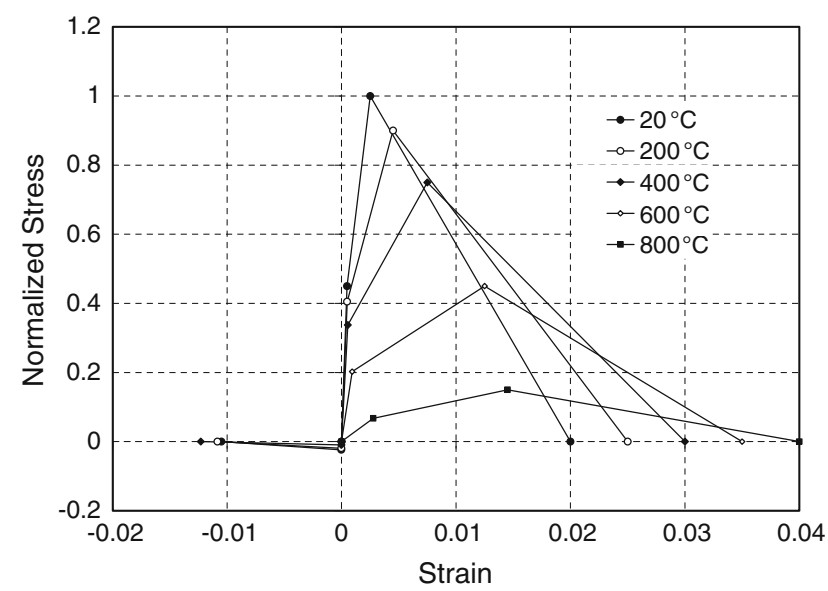

Fig. 1 Concrete uniaxial loading behavior under elevated temperature. 
numerical simulation performed by Lim et al. (2004) and Moss et al. (2008). Ghaffar (2005) define $f_{t}$ as $0.3 f_{r}$, where $f_{r}$ is the concrete modulus of rupture.

Finite element analyses using different parameters for concrete tensile behavior and dilation ratios are conducted to simulate the tests of Specimens B-2 and B-4. From the analyses, $f_{t}=0.2 f_{r}$ and $\varepsilon_{t u}=10 f_{c} / E_{c}$ are calibrated to ensure converged results and to avoid significantly underestimated stiffness of slabs. It is also found that the load-deformation response of slab-column connections is not sensitive to dilation angle, which is thus taken as $15^{\circ}$. Figure 2 compares for the two specimens the measured load-center deflection response with that predicted from analysis using the calibrated modeling parameters. Acceptable agreement is achieved between the simulation and test results. To further validate the finite element simulation, the predicted slab section rotation and rebar force are examined. Figure 3 shows the plan view of slab section rotation about Y-axis in Specimen B-2 when the largest slab center deflection in the test $(23 \mathrm{~mm})$ is reached. It is seen that fairly small difference exists in slab rotation at the sections outside the vicinity of column, indicating that slab deforms mainly through rigid body rotation due to the highly localized flexural deformation near the column caused by concrete cracking and reinforcement yielding. Although such a property was not

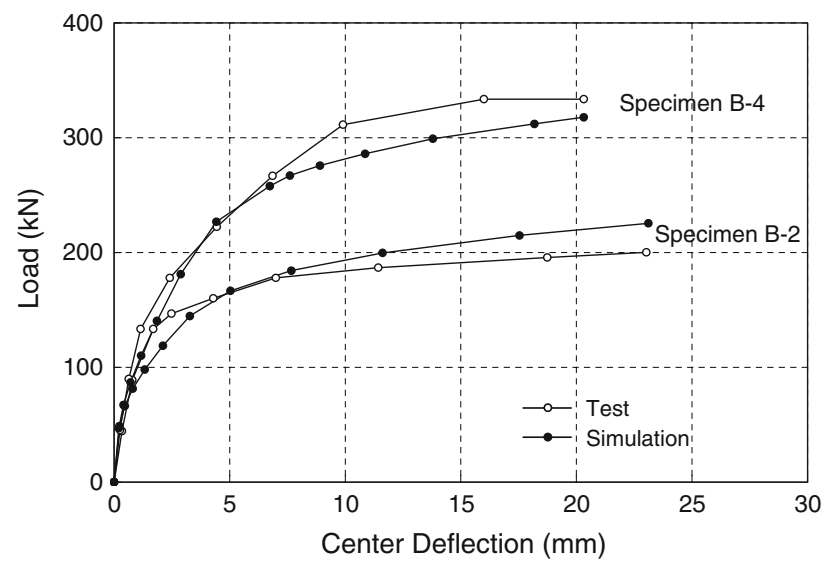

Fig. 2 Predicted versus measured load-center deflection response for Specimen B-2.
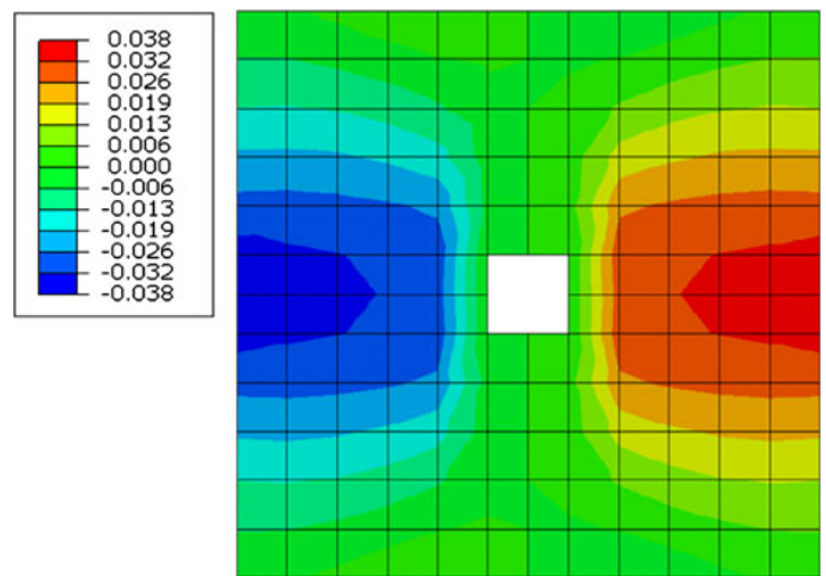

Fig. 3 Slab Rotation for Specimen B-2 at center deflection $=23 \mathrm{~mm}$ (unit: radian). specifically reported by Elstner and Hognestad (1956), it is consistent with the observation made from the similar tests by Guandalini et al. (2009).

Figure 4 shows for Specimen B-2 the forces in slab tensile reinforcement oriented in $\mathrm{X}$-direction when this specimen is loaded to a center deflection of $23 \mathrm{~mm}$. Based on the reported material properties, the rebar had a yield force of $9.1 \mathrm{kips}$ $(2.05 \mathrm{kN})$. According to this yield force, the reinforcement located in the regions denoted by the red and orange colors in Fig. 4 has yielded or is close to yielding. The forces of the reinforcement in Y-direction are developed in a similar manner. The yielding pattern identified from finite element simulations is compared with the yield lines (the dot lines in Fig. 4) derived from yield-line theory. The yield-lines, consistent with the distribution of widely opened slab cracks observed in the tests by Elstner and Hognestad (1956), develop at slab-column interface and extend from column to slab edges located 446-mm from the nearest slab corners. It is seen from Fig. 4 that the yielding of rebar predicted from analysis has extended to a large region of the slab following a pattern comparable to the theoretical yield lines.

\subsection{Thermal Properties of Slab Concrete}

Neglecting the evaporation of free water in concrete, the mass density of concrete is taken constant. Both ASCE (1992) and EC2 (1992) have specified specific heat, thermal conductivity, and thermal expansion for siliceous concrete. The two sources define specific heat and thermal conductivity similarly except that the specific heat defined in ASCE (1992) spikes between 400 to $600{ }^{\circ} \mathrm{C}$ due to the assumed presence of quartz and the thermal conductivity defined in EC2 (1992) reduces at a slightly lower rate with increased temperature. However, significant difference exists between ASCE (1992) and EC2 (1992) in defining concrete thermal expansion, a critical parameter for obtaining desirable analysis results of concrete slabs (Huang et al. 1999). To examine the appropriateness of these concrete thermal property models, finite element simulations are performed on the three specimens tested by Lim and Wade (2002). The time-temperature histories measured at slab bottom surface in the tests are applied at this location in the analyses. Temperatures are assumed identical over the slab and therefore vary only through the thickness of slab.

Heat transfer analyses are conducted first using the different definitions for specific heat and thermal conductivity given by ASCE (1992) and EC2 (1992). As mentioned previously, the heat transfer of a reinforced concrete slab is largely unaffected by the presence of reinforcement. Therefore, slab reinforcement is not included into this type of analysis. The temperatures determined from analyses are compared with those measured from tests at several locations along slab depth. It is found that ASCE's formulations result in slightly better prediction. Figure 5 shows a group of time-temperature curves for Specimen HD 12, each corresponding to the temperature at a certain distance from the heated slab bottom surface. As seen in Fig. 5, the analyses using ASCE's recommendation for concrete specific heat and thermal conductivity fairly well predict slab temperatures within 90 min of heating, the design fire endurance for the prototype building to be analyzed. 


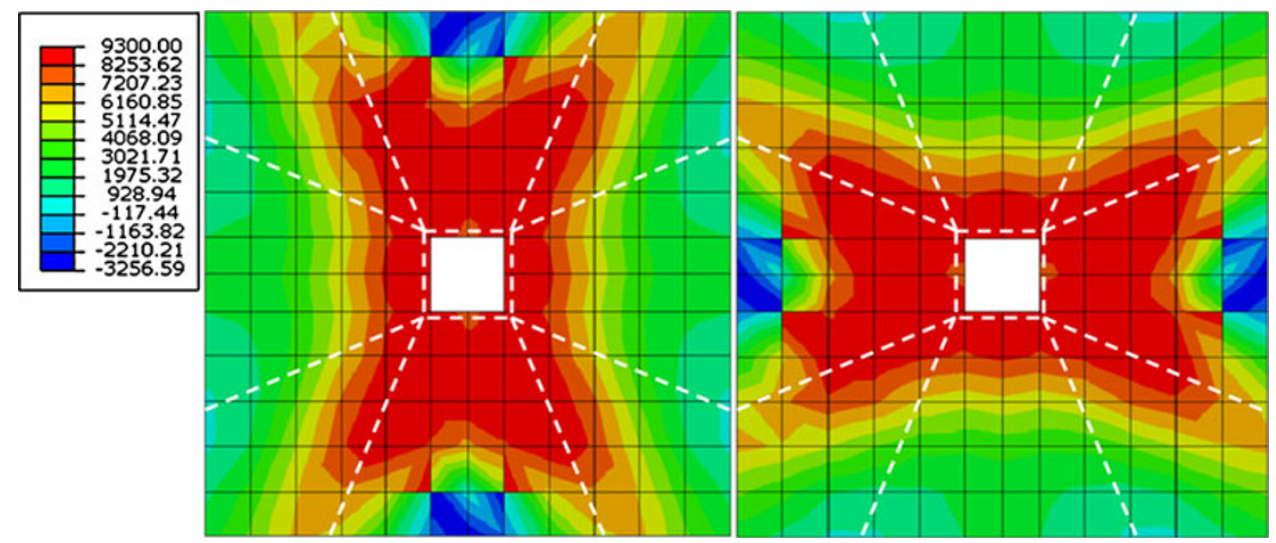

Fig. 4 Force in slab tensile reinforcement and yield lines for Specimen B-2 at center deflection $=23 \mathrm{~mm}$ (unit lb).

Beyond this time, the temperature near the unheated slab surface is overestimated.

Based on the temperature field in slab determined from heat transfer analyses, structural analyses are then conducted on the three specimens using the concrete thermal conductivity specified by ASCE (1992) and EC2 (1992). Focus is given to the center deflections of slabs under combined gravity and thermal loads. Note that such deformation results from the coupled effects of mechanical and thermal properties of materials. Figure 6 compares the predicted and measured slab center deflections for the three tests. This figure suggests that the analyses using the concrete thermal expansion defined by ASCE (1992) can much better capture the slab deflection response. According to the aforementioned heat transfer and structural analyses, the three thermal properties (specific heat, thermal conductivity, and thermal expansion) of concrete defined in ASCE (1992) will be adopted in the following numerical simulation.

\section{Analysis of a Flat Plate Building Exposed to Fire}

\subsection{Description of Prototype Structure}

The prototype flat plate structure, as shown in Fig. 7, is a four story office building designed with $1.5 \mathrm{~h}$ fire resistance.

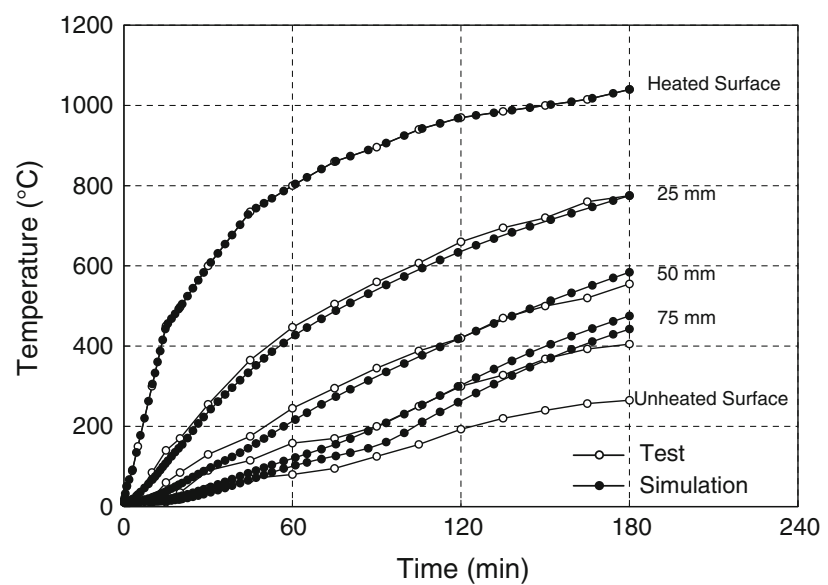

Fig. 5 Predicted versus measured temperatures for Specimen HD12.
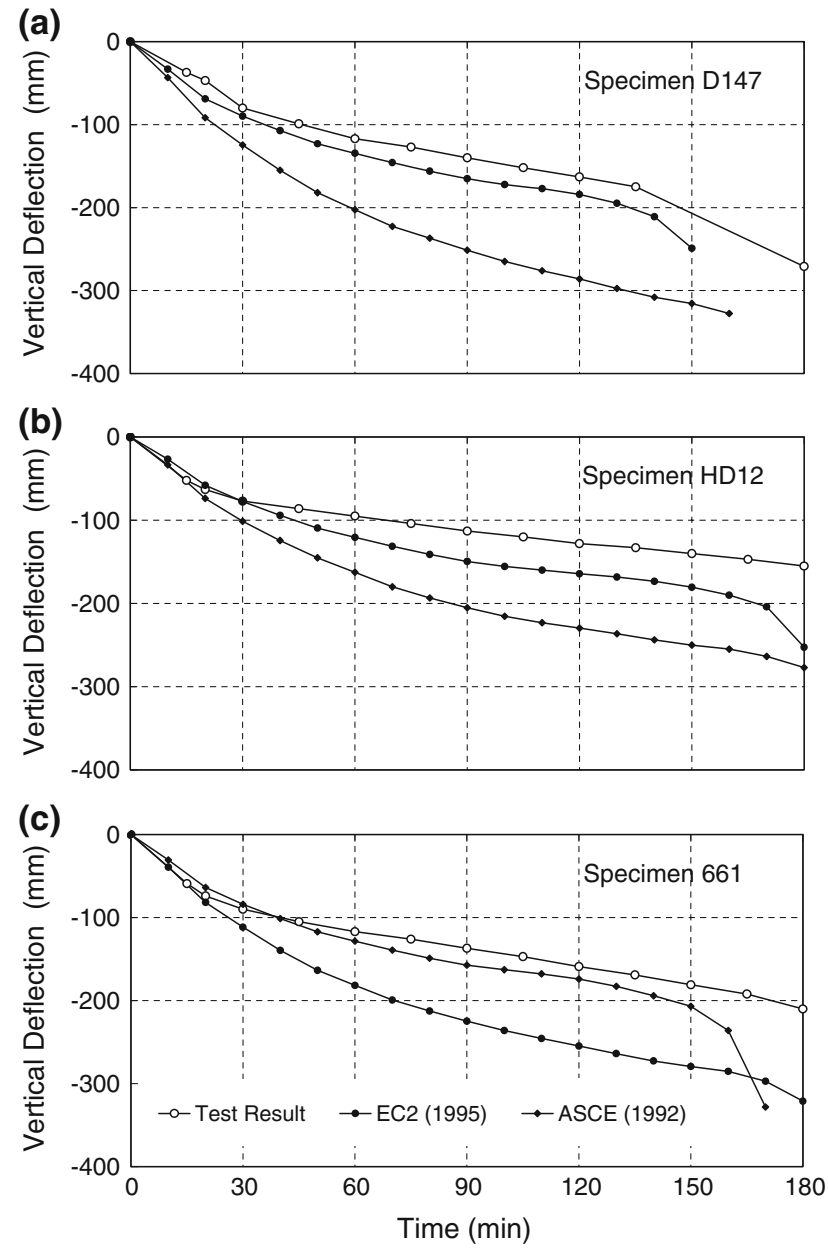

Fig. 6 Predicted versus measured slab center deflection due to elevated temperature for three specimens.

The building has a $3.05 \mathrm{~m}$ story height and four bays in each direction spanning $6.1 \mathrm{~m}$ between column centers. It is assumed that gravity loads control the design and thus no lateral load systems such as perimeter moment frames or shear walls are employed. The design of this prototype structure follows the building design codes ASCE 07-10 (2010), ACI 318-11 (ACI committee 318 2011), and ACI 216.1-07 (Joint ACI/TMS Committee 216 2007). The design gravity loads on each floor consist of slab self-weight plus $1.44 \mathrm{kN} / \mathrm{m}^{2}$ superimposed dead load and $2.39 \mathrm{kN} / \mathrm{m}^{2}$ live load. The slabs are supported on $381 \mathrm{~mm}$ square columns

114 | International Journal of Concrete Structures and Materials (Vol.6, No.2, June 2012) 


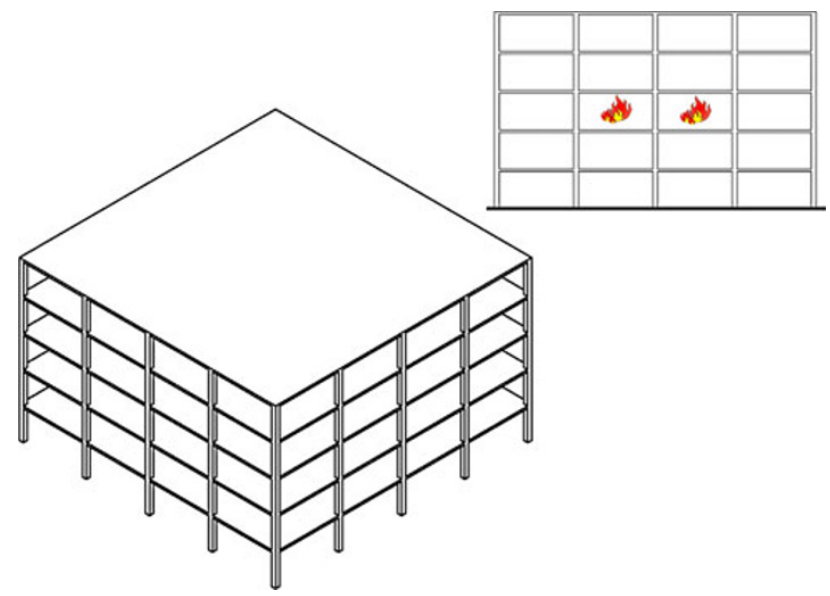

Fig. 7 Prototype flat plate building.

without using shear capitals or drop panels. Grade 60 hotrolled reinforcement (yield strength $f_{y}=414 \mathrm{MPa}$ ) and normal weight concrete with a cylinder compressive strength of $27.6 \mathrm{MPa}$ are used to construct the slabs and columns. The concrete is made of siliceous aggregates with $9.53 \mathrm{~mm}$ maximum size.

The direct design method provided in ACI 318-11 (2011) is used to design the slabs. The slab thickness is chosen as $191 \mathrm{~mm}$ to satisfy the code requirements regarding deflection serviceability and two-way shear strength. The clear cover of slab flexural reinforcement is $19.1 \mathrm{~mm}$. The slab thickness and the size of concrete cover satisfy the requirements in ACI 216.1-07 (2007) for obtaining $1.5 \mathrm{~h}$ fire resistance. Same design layout of slab reinforcement, shown in Fig. 8 for a quarter of the slab based on symmetry, is applied to all stories. No. 4 bars (diameter $12.7 \mathrm{~mm}$ ) are used for all slab reinforcement. The slab top reinforcement ratio is $0.53 \%$ at the interior slab-column connections and $0.27 \%$ at the exterior connections. The design of slab top and bottom reinforcement at the middle strips is governed by the code minimum reinforcement requirements to control cracking due to shrinkage and normal temperature changes. This minimum reinforcement requirement is also enforced for slab top bars because the negative bending moment may be developed over the entire slab at high temperatures.

Fire is assumed to occur in the center bays on the third floor. The actual temperature in a fire compartment depends on several parameters such as fuel load and ventilation. Estimating the probable fire temperature is beyond the scope of the present study. Thus, the time-temperature history identical to that measured at slab bottom during the furnace testing of Specimen HD12 (Lim and Wade 2002) is applied in analysis at slab bottom surface while the slab top surface has room temperature at the beginning of heating. It is assumed that in the event of fire the prototype structure is subject to a uniformly distributed gravity load of $1.0 \mathrm{D}+0.25 \mathrm{~L}$, where $\mathrm{D}$ and $\mathrm{L}$ are the design dead load and live load given previously.

\subsection{Finite Element Model for Prototype Structure}

As shown in Fig. 9, only a quarter of the prototype structure is modeled using symmetry to reduce computation cost. The slab is restrained in three degrees of freedom along the
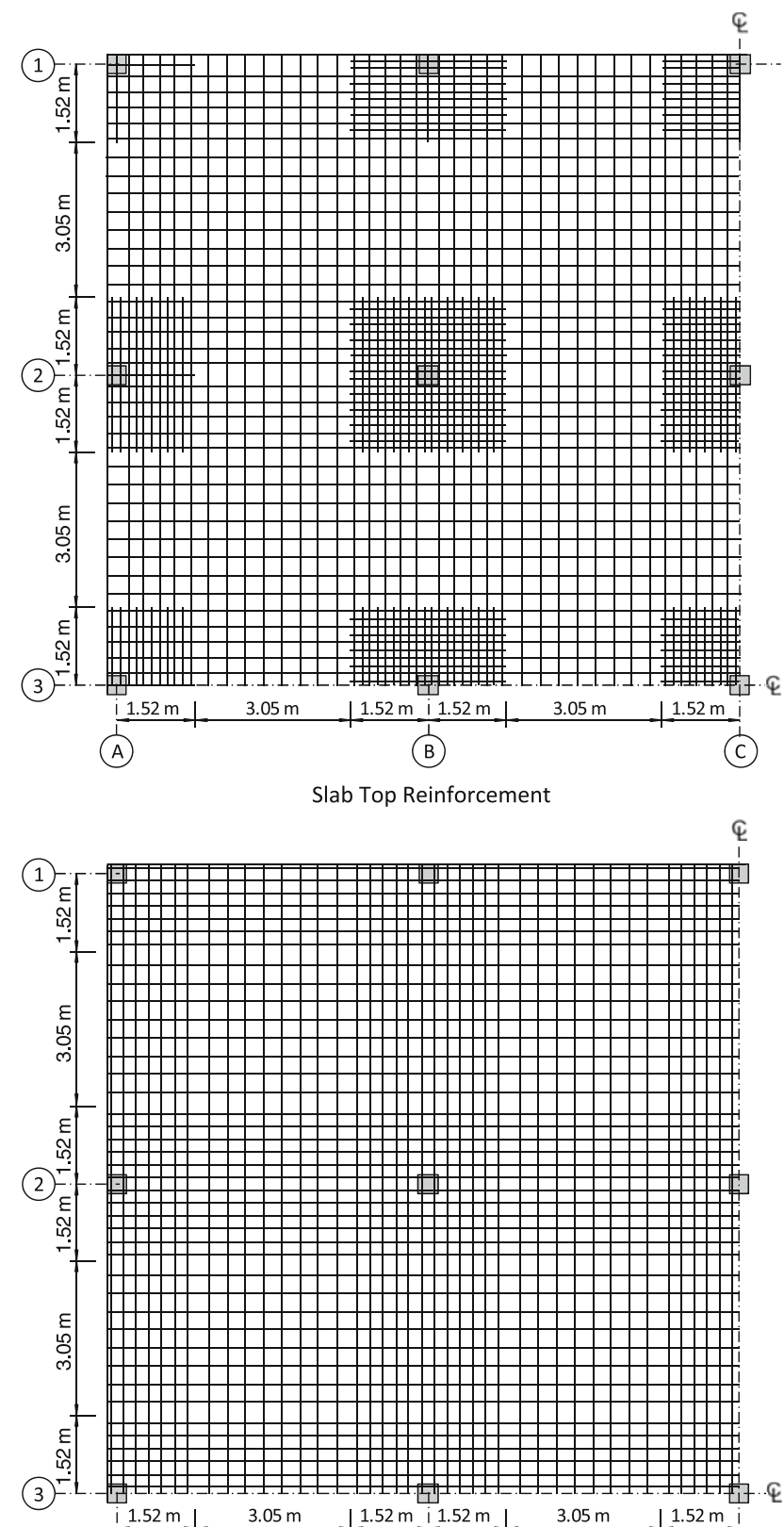

(A) B

Slab Bottom Reinforcement

Fig. 8 Slab reinforcement layout of prototype building.

two edges representing the floor centerlines but unrestrained along the two other edges. Approximate boundary conditions are applied to the columns: the columns below the slab are fully fixed at the bottom while the top of the columns above the slab are permitted only to move vertically. The material properties calibrated previously are used to simulate the reinforced concrete slabs. Each column is modeled by five line elements. It is assumed that the fire primarily impacts the slab and no flexural or shear failure occurs in the columns. Therefore, the columns are modeled as linear elastic. However, the flexural stiffness of the columns is taken as $70 \%$ of that for uncracked sections to account for stiffness degradation due to fire exposure and concrete cracking in columns caused by slab in-plane expansion. For convenience of presenting analysis results, nine reference points are defined in the quarter prototype structure, as shown in Fig. 9. Points A 

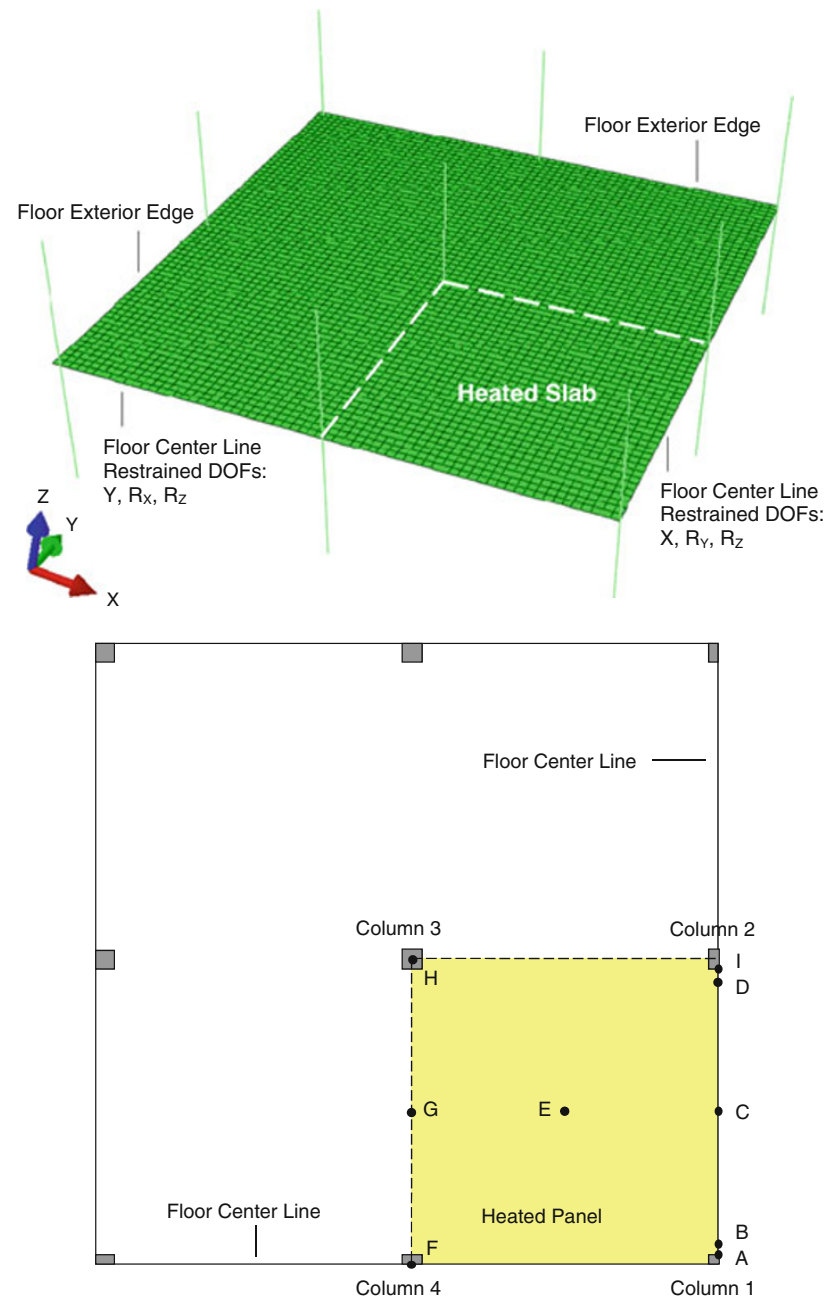

Fig. 9 Finite element model for prototype structure.

and I are located at the slab-column interface. Points B and D are located at a distance of $191 \mathrm{~mm}$ (slab thickness) from the column surface. Points $\mathrm{H}$ and $\mathrm{F}$ are at the center of Columns 3 and 4. Point $\mathrm{E}$ is located at the center of the heated slab panel. Points $\mathrm{C}$ and $\mathrm{G}$ are situated at the mid-span between columns.

\subsection{Analysis Results and Discussions \\ 3.3.1 Results of Heat Transfer Analysis}

Heat transfer analysis is conducted first on the finite element model of the prototype structure. Figure 10 shows the calculated temperature varying over thickness of the heated slab. The temperature of top reinforcement increases slowly to $129{ }^{\circ} \mathrm{C}$ at $3 \mathrm{~h}$. The temperature of bottom reinforcement increases from the initial 20 to $657^{\circ} \mathrm{C}$ at $1.5 \mathrm{~h}$, and continues to increase to $841{ }^{\circ} \mathrm{C}$ at $3 \mathrm{~h}$. According to the mechanical model for reinforcing steel used in this study, the yield strength of slab bottom reinforcement at $1.5 \mathrm{~h}$ (the design fire resistance of the prototype building) has been reduced to $22 \%$ of that at room temperature. Thus, the elevated temperature at $1.5 \mathrm{~h}$ can cause significantly reduced flexural capacity of the heated slab for resisting positive bending moment.

\subsubsection{Slab Vertical Deflection}

Following the heat transfer analysis, structural analysis is performed. The analysis cannot complete the entire 3-hour

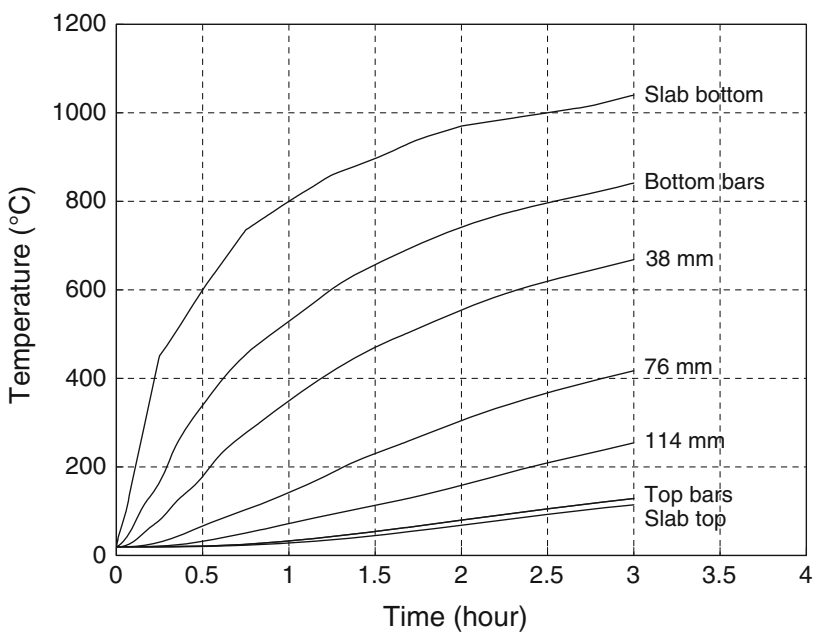

Fig. 10 Predicted temperature inside heated slab.

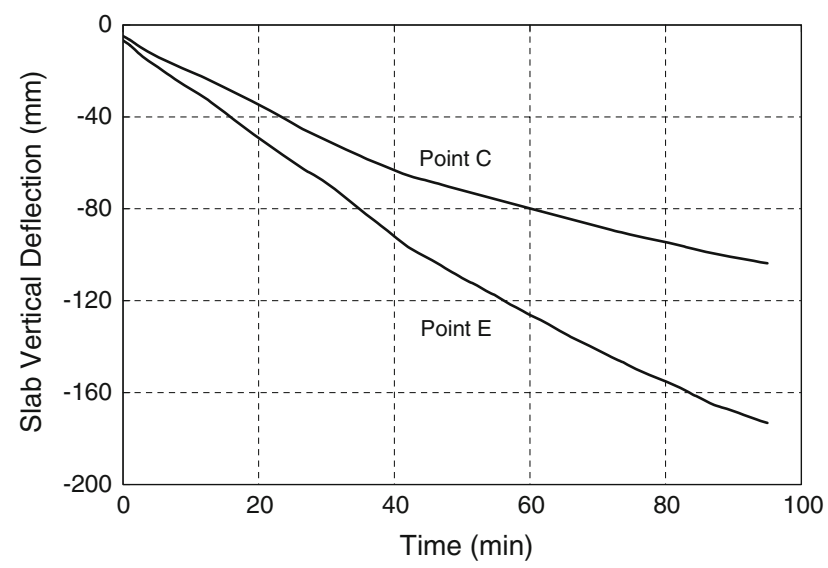

Fig. 11 Slab vertical deflections at Points $C$ and $E$.

fire loading and divergences at $95 \mathrm{~min}$. However, because the prototype building is designed with $1.5 \mathrm{~h}$ fire resistance, the analysis still provides critical information regarding the fire performance of the structure. Figure 11 shows the vertical displacement of the slab at Points $\mathrm{C}$ and $\mathrm{E}$. The initial gravity load causes a deflection of 4.79 and $6.69 \mathrm{~mm}$ at $\mathrm{C}$ and E, respectively. After the thermal load is applied, the deflection at $\mathrm{E}$ increases at a higher rate than at $\mathrm{C}$. Upon 95 min of heating, the slab deflections at $\mathrm{C}$ and $\mathrm{E}$ have reached 104 and $173 \mathrm{~mm}$, respectively. However, at this loading stage there is no sign of reaching a collapse mechanism associated with flexural yielding because the slab has not experienced a rapid increase in deflection at either location. The deflected shape of the prototype structure is shown in Fig. 12 for 30, 60, and 90 min of fire loading. The largest deflection always occurs at the center of the heated slab panel.

\subsubsection{Slab In-Plane Expansion and Membrane Forces}

The thermal expansion of the heated panel leads to steadily increased outward displacement at all locations. Figure 13 shows the distribution of horizontal displacement in the entire slab at $90 \mathrm{~min}$. Points $\mathrm{G}$ and $\mathrm{F}$ experience similar in-plane displacements. At $90 \mathrm{~min}$ of heating, the in-plane 

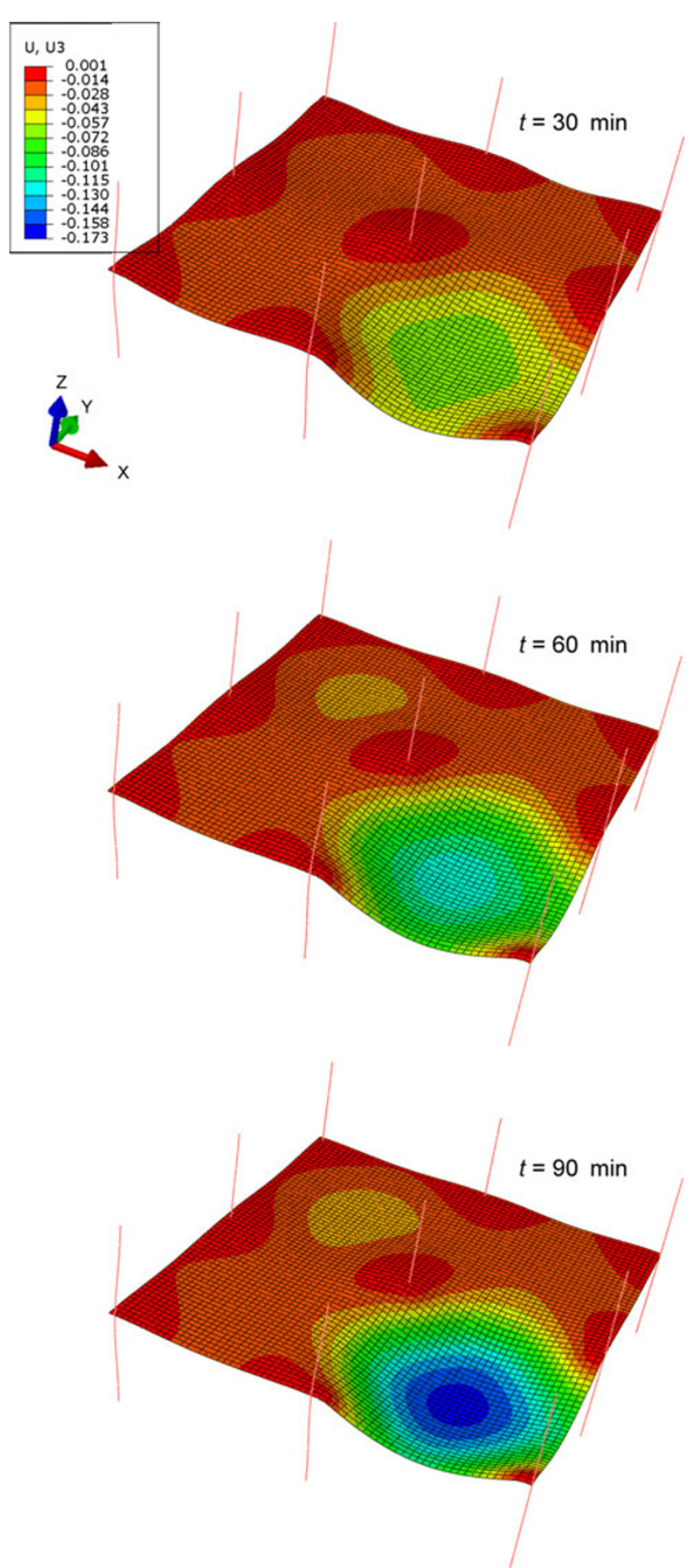

Fig. 12 Slab vertical displacement at $t=30,60$, and $90 \mathrm{~min}$ (unit $\mathrm{m}$ ).

displacement at $\mathrm{F}$ is $21 \mathrm{~mm}$, a lateral deformation large enough to cause column cracking. Figure 14 shows the slab membrane force per unit width in the $\mathrm{X}$-direction at Points A, C and E. Gravity loading causes tensile membrane forces at Points $\mathrm{C}$ and $\mathrm{E}$ and compressive membrane force at Point A. However, because the thermal expansion of the heated panel is restrained by the surrounding slab and columns, compressive in-plane forces are developed during thermal loading. After 3 min of heating, the slab sections at all the three locations are in compression. The rate of increase in compressive force is significantly reduced after $20 \mathrm{~min}$ of

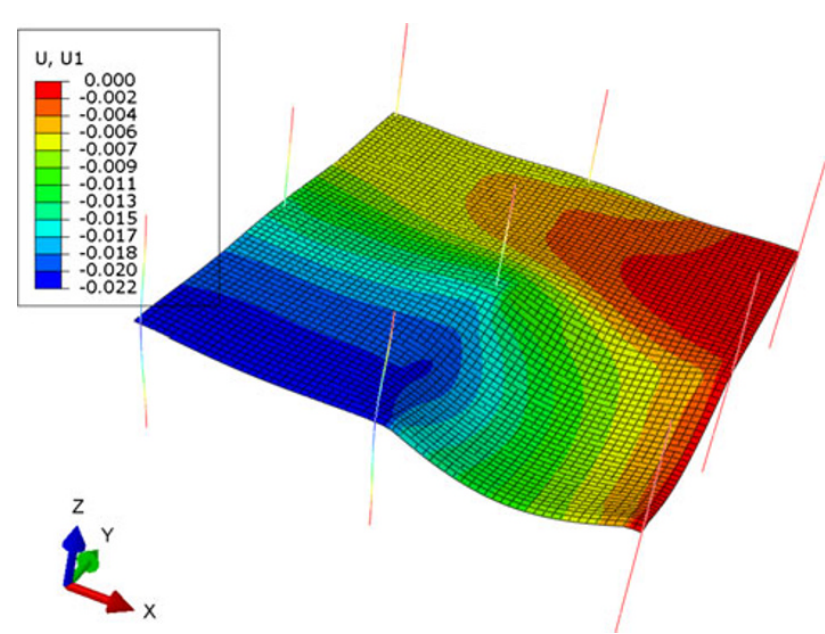

Fig. 13 Slab in-plane displacement at $t=90 \min$ (unit m).

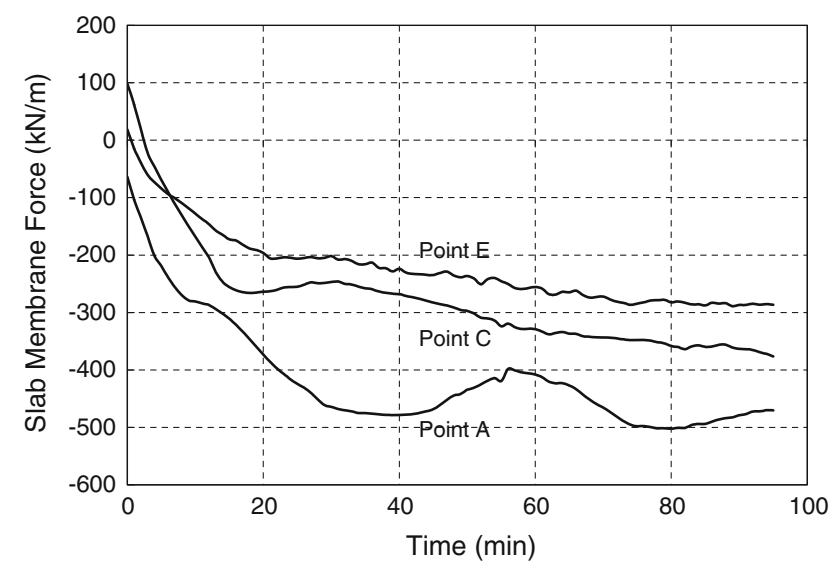

Fig. 14 Slab membrane forces at Points $A, C$, and E.

heating for the slab sections at $\mathrm{C}$ and $\mathrm{E}$ and after 30 min for the slab section at $\mathrm{A}$. The largest compressive membrane force always occurs at section $\mathrm{A}$, where the peak compressive membrane force $(500 \mathrm{kN} / \mathrm{m})$ is achieved at $80 \mathrm{~min}$.

\subsubsection{Bending Moments and Rebar Forces in Slab}

Figure 15 shows the bending moments about $\mathrm{X}$-axis per unit width of slab at Points A, C, E, and I. The initially applied gravity load causes positive bending moment (slab bottom in tension, negative sign in Fig. 15) at mid-span points $\mathrm{C}$ and $\mathrm{E}$, and negative bending moment (slab top in tension, positive sign in Fig. 15) at column points A and I. Due to stress concentration, the negative bending moment near columns is about eight times the positive bending moment at $\mathrm{C}$ and $\mathrm{E}$. Figure 15 indicates that moment redistribution occurs rapidly as the temperature increases. The moment redistribution causes the slab sections near columns (Points A and I) to reach yielding moment at approximately four min, and quickly switches the positive moment at Points $\mathrm{C}$ and $\mathrm{E}$ into negative bending moment. Beyond $30 \mathrm{~min}$ of heating, the bending moments at these locations experience little change. Similar trend of moment redistribution can also be observed in Fig. 16, which shows the slab bending moment about $\mathrm{X}$-axis for the entire slab at 0,30 , and $90 \mathrm{~min}$. It is seen from this figure that all the slab sections in the heated panel at 30 min resist only negative 


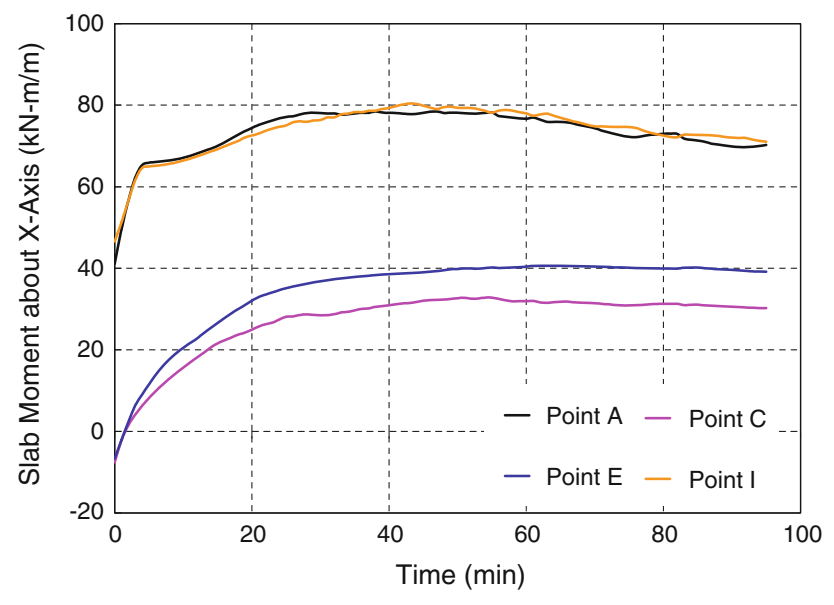

Fig. 15 Slab bending moments about $\mathrm{X}$-axis at Points $\mathrm{A}, \mathrm{C}$, $\mathrm{E}$, and I.

bending moment and the moment distribution at $90 \mathrm{~min}$ is very similar to that at $30 \mathrm{~min}$. The stabilized moment distribution can be explained by the fact that, once yielding occurs in the slab near columns, the columns stop restraining slab section rotation caused by temperature gradient. Figure 16 indicates that moment redistribution caused by thermal loading also occurs in the unheated slab panels but is much less severe than in the heated panel.

Interpreting the slab bending moment characteristics can be aided by examining slab rebar forces. Figure 17 shows the forces in the slab top and bottom reinforcement resisting moment about X-axis at Points A, C, E, and I. Tensile force is assigned as positive. It is seen that the reinforcement at Points A and I near columns present almost identical response. Consistent with the quick reach of a yield moment as shown in Fig. 15, the top reinforcing bars at these locations yield at $\sim 4 \mathrm{~min}$. The compressive force in the bottom bars keeps increasing until $40 \mathrm{~min}$ when the temperature of the bottom bars has exceeded $400{ }^{\circ} \mathrm{C}$ and strength degradation of steel has started. At Points $\mathrm{C}$ and $\mathrm{E}$, the initial tensile force in the bottom reinforcement quickly changes sign. Even though the top reinforcement at $\mathrm{E}$ becomes in tension after $8 \mathrm{~min}$ of heating, this process takes about $24 \mathrm{~min}$ for the slab section at C. From $50 \mathrm{~min}$ to $90 \mathrm{~min}$, the compressive rebar force at $\mathrm{C}$ and $\mathrm{E}$ experiences only slight decrease.

\subsubsection{Slab Section Rotation}

Figure 18 shows slab section rotation with respect to X-axis at Points B and D located $191 \mathrm{~mm}$ (slab thickness) from column face. Similar response is presented at these locations. Gravity loading causes limited slab flexural deformation and thus negligible section rotation. Slab rotation increases slowly during the initial heating but increases at a much higher rate after 4 min of thermal loading when yielding is initiated in slab near the columns. Figure 19 shows the distribution of slab rotation about X-axis at 30, 60, and $90 \mathrm{~min}$. It is seen that slab rotation is highly localized at columns. The deformed shape of the slab as well as the similar rotation contours at the columns surrounding the heated panel indicates that the heated slab in the vicinity of columns deforms approximately as a rigid body. It shall be

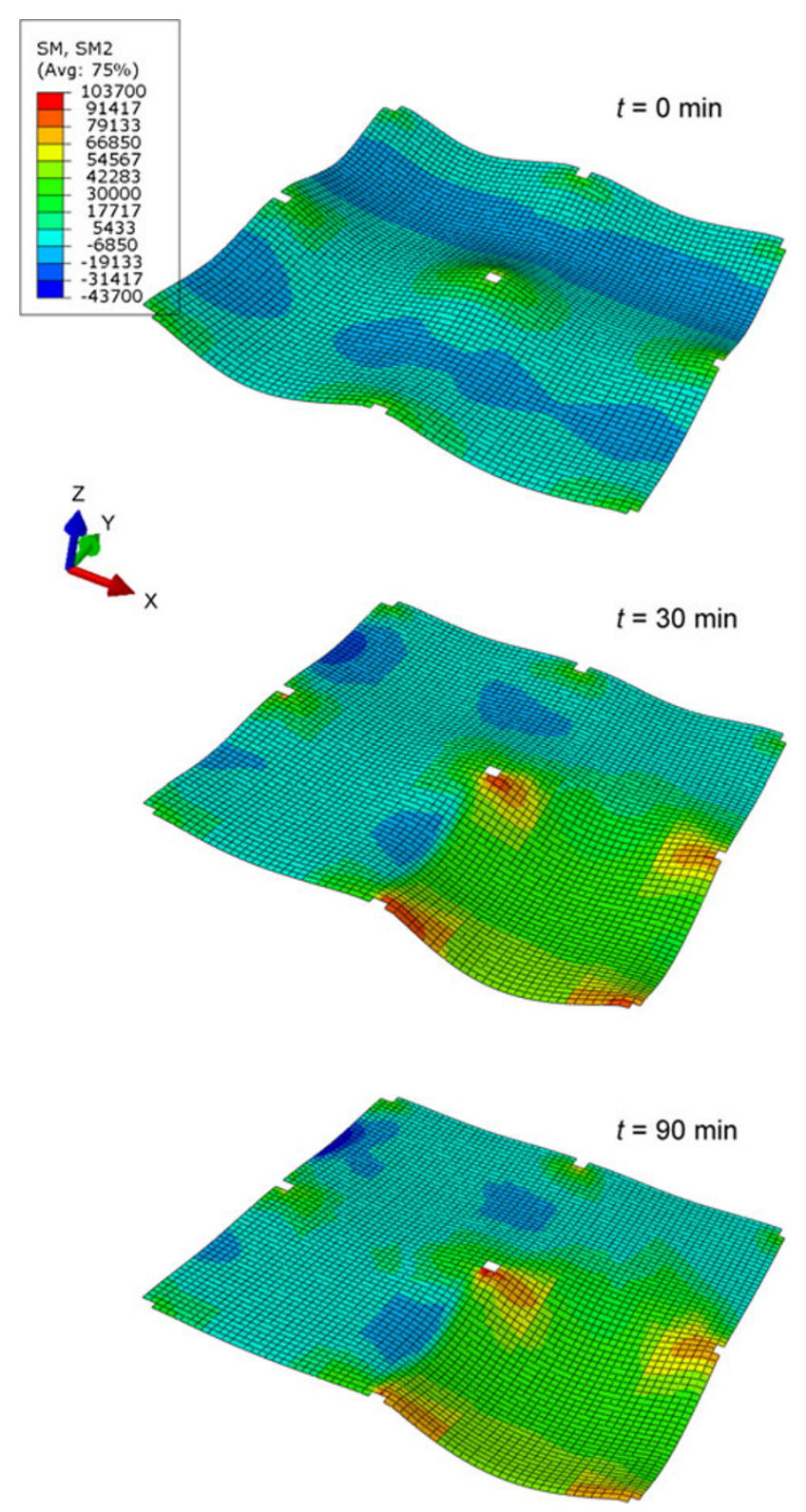

Fig. 16 Slab bending moments about $\mathrm{X}$-axis at $t=0,30$, and 90 min (unit kN/m).

noted from Figs. 18 and 19 that the rotation of slab relative to column at $90 \mathrm{~min}$ has reach as high as nearly 0.06 radians. The wide crack opening associated with the large slab rotation probably has deeply extended the inclined crack and significantly weakened aggregate interlocking force that contributes to connection shear strength. Additionally, during the tests reported in the various previous studies (Elstner and Hognestad 1956; Guandalini et al. 2009; Tian et al. 2008), none of the isolated slab-column specimens without using shear reinforcement could survive such a large deformation without any punching failure. Thus, the excessive local deformation of slab likely poses high risk of punching failure of slab-column connections.

\subsubsection{Risk of Punching Failure of Slab-Column Connections}

There is virtually no test data available for the punching shear strength of flat plate structures under fire conditions. 

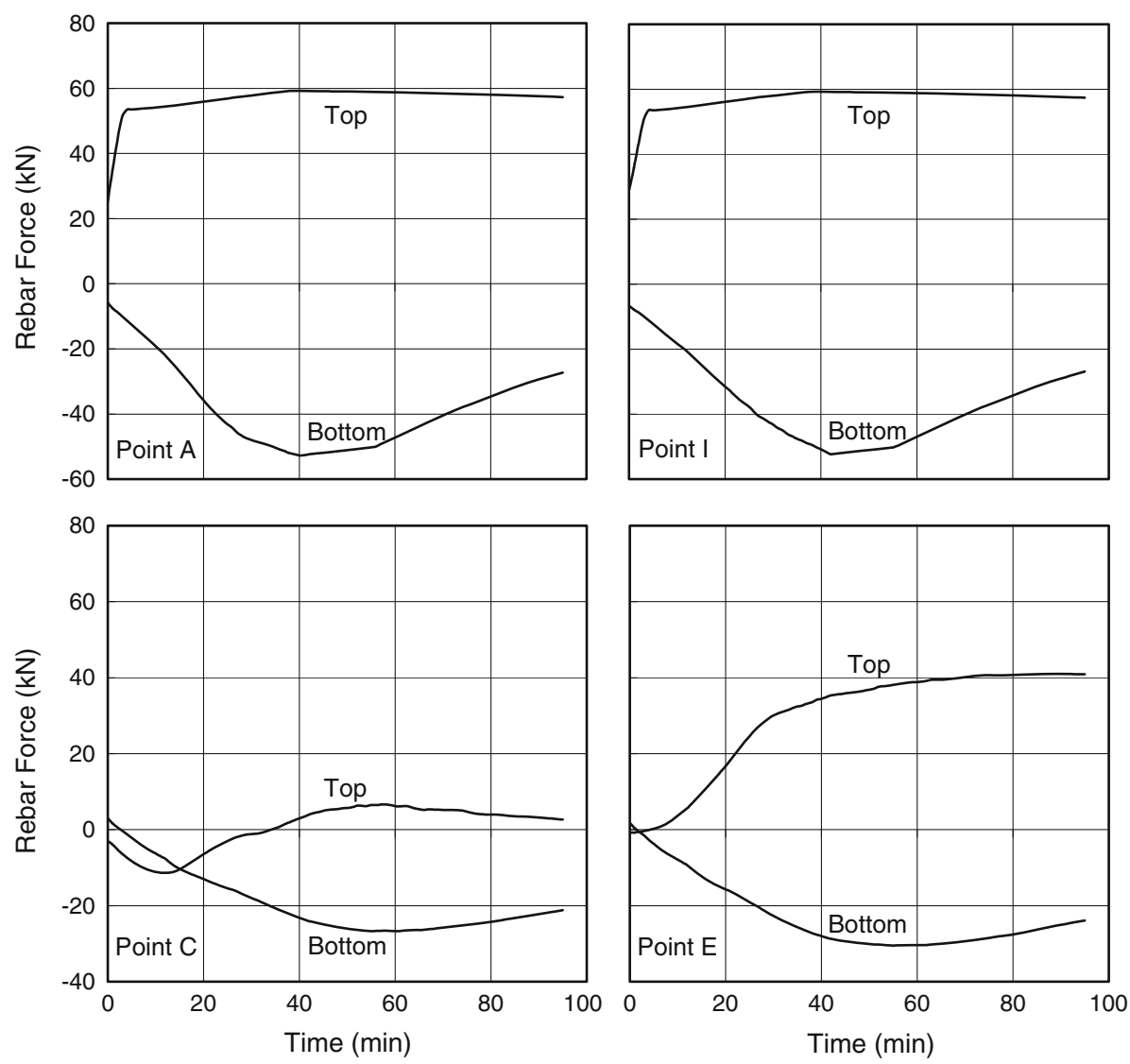

Fig. 17 Rebar forces at Points A, C, E, and I.

EC2 (1992) suggests that the shear strength of a reinforced concrete beam or column can be evaluated using conventional approach based on the reduced cross-section where the temperature is less than $500{ }^{\circ} \mathrm{C}$. Should this approach be applied to slab-column connections, it would imply that only the upper portion of the slab with low temperatures is effective to resist shear, a treatment in direct contradict to the actual behavior of slab-column connections. As shown in Fig. 20, the inclined shear crack is initiated from slab top surface and the shear resistance may be provided mainly by the slab concrete underneath the tip of inclined crack, i.e. the lower portion of slab. Therefore, it is debatable to use EC2's approach to evaluate the punching shear strength of slabcolumn connections under elevated temperature.

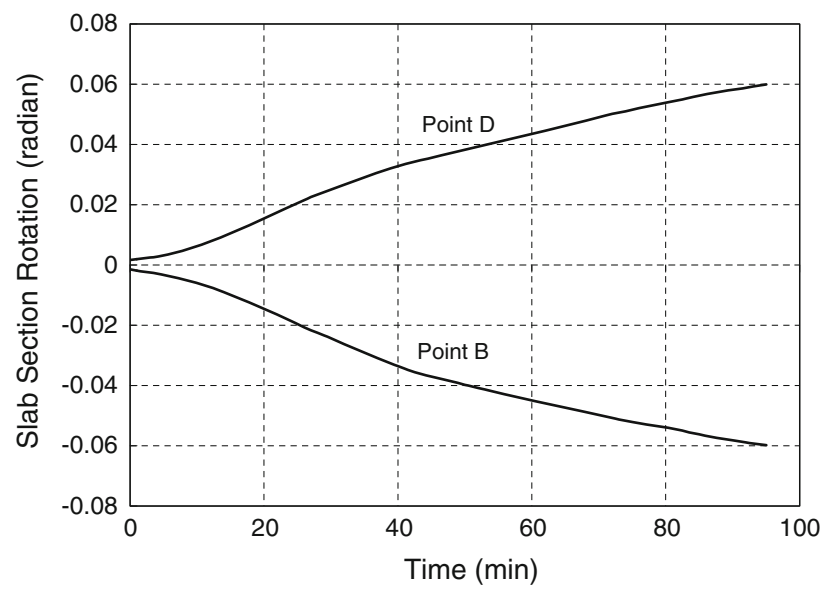

Fig. 18 Slab section rotation about $X$-axis at Points B and D.
Tests (Elstner and Hognestad 1956; Guandalini et al. 2009; Tian et al. 2008) indicated that prior to punching failure slab has experienced flexural yielding near the column and, following the yielding, slab deforms as a rigid body until punching failure occurs. Thus, the punching failure of slab-column connections, especially those with low-to-moderate slab tensile reinforcement ratios, can be interpreted as the result of large curvature of slab near the column. Accordingly, Muttoni's (2008) formulation for the punching strength of slab-column connections without shear reinforcement is adopted in this study. Based on a critical shear crack theory and the data of 99 tests, Muttoni (2008) defined the punching strength as a function of the rotation of slab outside inclined shear crack. According to this theory, the opening of inclined crack reduces the capability of concrete under compression to resist punching failure. The width of inclined crack was assumed to be proportional to $\theta d$, where $\theta$ is the rotation of slab relative to column and $d$ is the effective depth of slab. The punching strength $V_{R}$ was then correlated with slab rotation at failure $\theta_{u}$ as

$$
V_{R}=\left(\frac{0.75}{1+15 \frac{\theta_{u} d}{d_{g 0}+d_{g}}}\right) b_{0} d \sqrt{f_{c}}(\text { in } \mathrm{N}, \text { mm units }),
$$

where $b_{0}$ is the perimeter of shear critical section taken as $d /$ 2 from the column face, $f_{c}$ is concrete compressive strength, $d_{g}$ is the maximum size of the aggregate, and $d_{g 0}$ is a reference aggregate size equal to $16 \mathrm{~mm}$. 

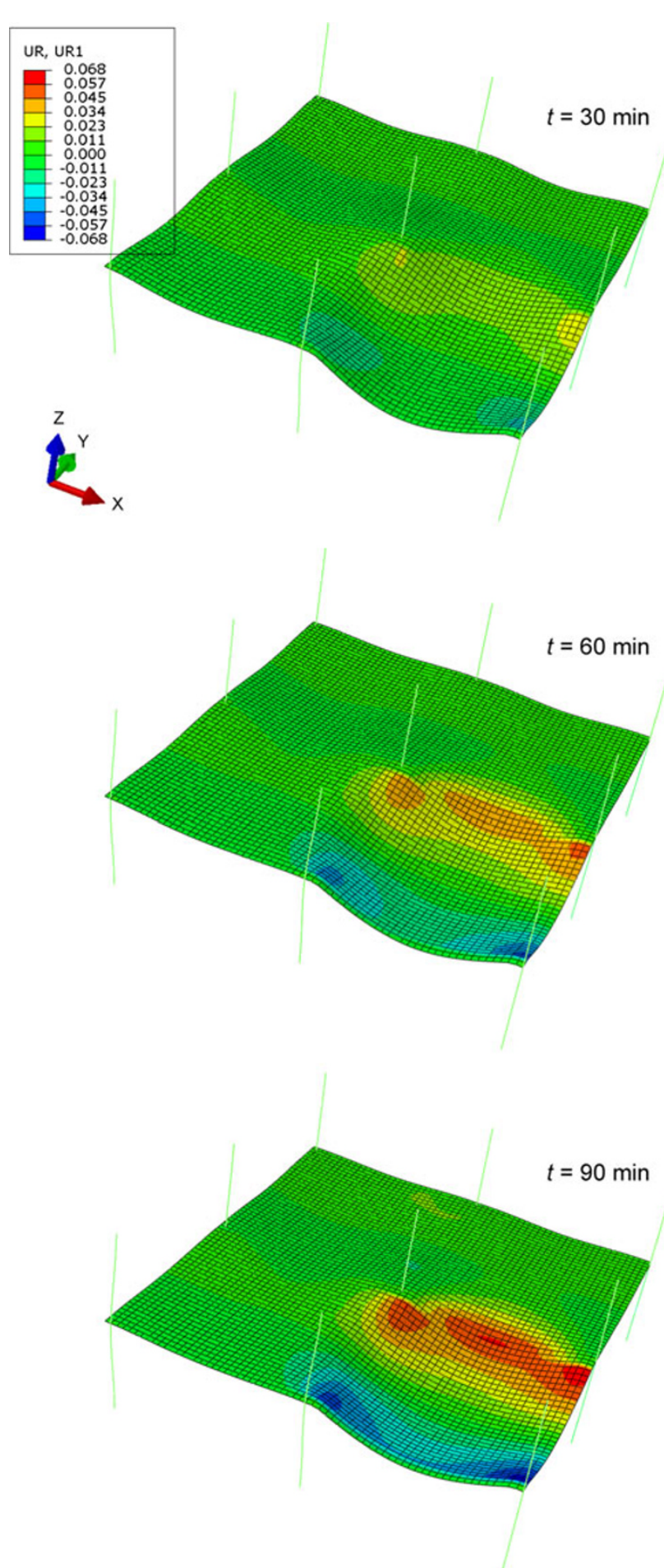

Fig. 19 Slab section rotation about $\mathrm{X}$-axis at $t=30,60$, and 90 min (unit radian).

When Eq. (1) is employed in the present study, the concrete strength $f_{c}$ is defined as a function of temperature according to EC2 (1992). Given that the temperature is not uniform over slab thickness, the temperature field determined from heat transfer analysis is used to estimate the concrete strength at different locations along the slab depth. It is assumed that the punching strength of a slab-column connection depends primarily on the depth of concrete underneath the inclined crack ( $h_{c}$ shown in Fig. 20) and the average concrete strength within $h_{c}$ is used to define $f_{c}$. Different values of $h_{c}$, ranging from $0.1 h$ to $0.9 h$ ( $h$ is slab

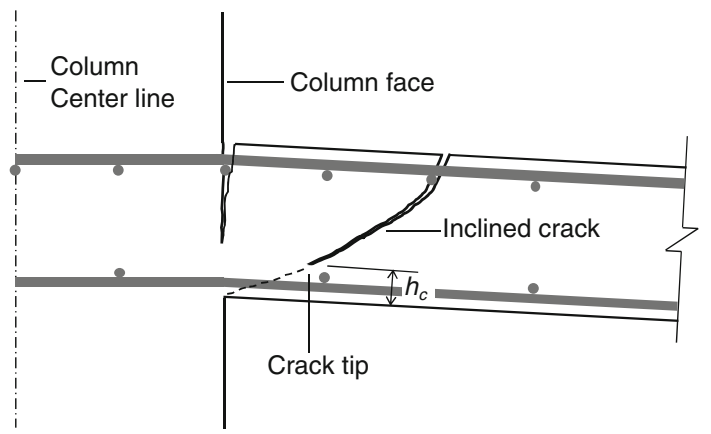

Fig. 20 Inclined crack at slab-column connection.

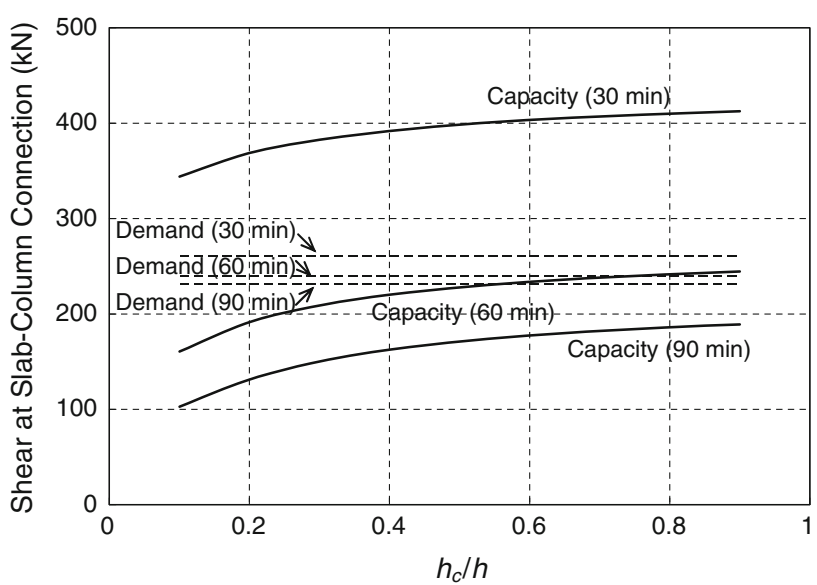

Fig. 21 Comparison of shear capacity and shear demand at $t=30,60$, and $90 \mathrm{~min}$.

depth), are assumed because its exact value is difficult to determine. The $0.9 h$ is chosen herein as an upper bound because it approximates the effective depth of slab.

Figure 21 compares the shear capacity at the center slabcolumn connection (Column 1) evaluated based on Eq. (1) and the shear demand determined from analysis at 30,60, and $90 \mathrm{~min}$ of heating. The dashed lines in the figure define the estimated shear capacity $V_{R}$ with different assumed $h_{c}$ values. The solid lines in Fig. 21 give the total shear transferred from slab to the center column, which varies slightly over time due to load redistribution. It appears from Fig. 21 that punching shear failure is unlikely to occur within $30 \mathrm{~min}$ of fire loading because the shear capacity is always higher than demand. However, this figure also indicates that, at $60 \mathrm{~min}$ of heating, punching strength will be less than shear demand if the depth of concrete in compression at the incline crack is assumed less than $70 \%$ of slab thickness $\left(h_{c}<0.7 h\right)$. Tian et al. (2008) tested three slab-column connections with a slab tensile reinforcement ratio of $0.5 \%$. The specimens were subjected to different loading histories until failure. It was observed from these tests that the slab inclined crack had deeply extended toward the interface of column and slab bottom surface prior to the ultimate punching failure. The prototype structure analyzed in the present study has a similar slab reinforcement ratio $(0.53 \%)$ at columns. It can therefore be assumed that $h_{c}<0.7 h$ and, accordingly, punching failure may occur earlier than $60 \mathrm{~min}$ of heating. Moreover, regardless of values assumed for $h_{c}$, 
the shear capacity at 90 min is much less than the shear that the slab-column connection must carry. In brief, the finite element simulation and the use of Eq. (1) indicate that, even if the prototype building is designed with $90 \mathrm{~min}$ fire endurance, premature punching shear failure may occur due to the large local deformation of slab caused by combined gravity and thermal loading.

\section{Conclusions}

Nonlinear finite element simulation using calibrated concrete thermal and mechanical properties is carried out on a flat plate building. The analysis indicates that, because the thermal-induced slab rotational deformation is restrained by columns, the slab top reinforcement near the columns yields quickly at around $4 \mathrm{~min}$ of heating. Consequently, the heated slab experiences severe bending moment redistribution that changes positive bending moment at the mid-span due to the initial gravity loading into negative moment. However, very little change in bending moment is seen between 30 and $90 \mathrm{~min}$ of heating. Due to the restrained thermal expansion, membrane forces in the slab become compressive at all sections after only a short period of thermal loading. Moreover, no collapse mechanism associated with slab flexural yielding is generated at $90 \mathrm{~min}$ of fire exposure.

This study reveals serious concern for the risk of punching failure at the interior slab-column connections of a flat plate building subjected to fire. The analysis carried out on the prototype building indicates that, if the depth of concrete underneath the inclined shear crack is less than $70 \%$ of the total slab depth, punching failure may have occurred at 60 min of heating. Even thought $90 \%$ of the slab section is assumed as effective in resisting shear, the shear demand will be much higher than the shear capacity after $90 \mathrm{~min}$ of fire loading. It is therefore concluded that, prior to reaching its design fire resistance, the prototype building may have suffered a premature punching shear failure due to the large curvature of slab near column.

\section{Open Access}

This article is distributed under the terms of the Creative Commons Attribution License which permits any use, distribution, and reproduction in any medium, provided the original author(s) and the source are credited.

\section{References}

ACI Committee 318. ( 2011). Building code requirements for structural concrete (ACI 318-11) and commentary. Farmington Hills, MI: American Concrete Institute.

ASCE. (1992). Structural fire protection. Manual No. 78. New York: ASCE Committee on Fire Protection, Structural Division, American Society of Civil Engineers.
ASCE 7-10. (2010). Minimum design loads for buildings and other structures. Reston, VA: American Society of Civil Engineers.

Dassault Systèmes Simulia Corporation. (2009). Abaqus 6.9 documentation.

Elstner, R. C., \& Hognestad, E. (1956). Shearing strength of reinforced concrete slabs. ACI Journal Proceedings, 53(1), 29-58.

Eurocode 2. (1995). Design of concrete structures. Part 1-2: General rules-structural fire design (ENV1992). Brussels: European Committee for Standardization.

Eurocode 3. (1995). Design of steel structures. Part 1-2: General rules-structural fire design (ENV 1993). Brussels: European Committee for Standardization.

Ghaffar, A., Chaudhry, M. A., \& Ali, M. K. (2005). A new approach for measurement of tensile strength of concrete. Journal of Research (Science), 16(1), 1-9.

Guandalini, S., Burdet, O. L., \& Muttoni, A. (2009). Punching tests of slabs with low reinforcement ratios. ACI Structural Journal, 106(1), 87-95.

Harmathy, T. Z. (1993) Fire safety design and concrete. Harlow: Longman Scientific \& Technical.

Huang, Z., Burgess, I. W., \& Plank, R. J. (1999). Nonlinear analysis of reinforced concrete slabs subjected to fire. $A C I$ Structural Journal, 96(1), 127-135.

Joint ACI/TMS Committee 216. (2007). Code requirements for determining fire resistance of concrete and masonry construction assemblies. Farmington Hills, MI: American Concrete Institute.

Lee, J., \& Fenves G. L. (1998). Plastic-damage model for cyclic loading of concrete structures. Journal of Engineering Mechanics, 124(8), 892-900.

Lim, L., Buchanan, A., Moss, P., \& Franssen, J. (2004). Numerical modelling of two-way reinforced concrete slabs in fire. Engineering Structures, 26(8), 1081-1091.

Lim, L., \& Wade, C. (2002). Experimental fire tests of two-way concrete slabs. Fire Engineering Research Report 02/12. Christchurch (New Zealand): University of Canterbury.

Lubliner, J., Oliver, J., Oller, S., \& Oñate, E. (1989). A plasticdamage model for concrete. International Journal of Solids and Structures, 25 299-329.

Moss, P. J., Dhakal, R. P., Wang, G., \& Buchanan, A. H. (2008). The fire behaviour of multi-bay, two-way reinforced concrete slabs. Engineering Structures, 30(12), 3566-3573.

Muttoni, A. (2008). Punching shear strength of reinforced concrete slabs without transverse reinforcement. $A C I$ Structural Journal, 105(4), 440-450.

Ruiz, M. F., Muttoni, A., \& Kunz, J. (2010). Strengthening of flat slabs against punching shear using post-installed shear reinforcement. ACI Structural Journal, 107(4), 434-442.

Tian, Y., Jirsa, J. O., Bayrak, O., Widianto, \& Argudo, J. F. (2008). Behavior of slab-column connections of existing flat-plate structures. ACI Structural Journal, 105(5), 561-569.

Vermeer, P. A., \& De Borst, R. (1984). Non-associated plasticity for soils, concrete, and rock. HERON, 29(3), 1-62.

Wang, G. (2004). Performance of reinforced concrete flat slabs exposed to fire. Fire Engineering Research report number 06/2. Christchurch (New Zealand): University of Canterbury. 